\title{
Efektivitas Corporate Social Responsibility (CSR) Energy Equity Epic Sengkang Pty. Ltd
}

\author{
Najeminur ${ }^{1}$, Andi Supriadi ${ }^{1}$, Herdi Syam ${ }^{2 *}$ \\ ${ }^{1}$ Fakultas IImu Administrasi Universitas Puangrimaggalatung \\ Jl. Sultan Hasannudin Maddukelleng Wajo 90918 Sulawesi Selatan \\ 2Jurusan Kemaritiman Politeknik Negeri Samarinda \\ Jl. Cipto Mangun Kusumo Kota Samarinda 75242 Kalimantan Timur
}

*Email: herdisyam3@gmail.com

Naskah diterima 30 Agustus 2021, Revisi 15 September 2021, Terbit 29 Oktober 2021

\begin{abstract}
DOI: doi.org/10.21107/pamator.v14i2.11980

The effectiveness of the Corporate Social Responsibility (CSR) program in Indonesia still needs to be improved. This can be seen from the number of companies that make CSR programs only a formality obligation without thinking about how much the benefits of the program are implemented for the community and the environment. This article discusses the effectiveness of Corporate Social Responsibility at Energy Equity Epic Sengkang Pty. Ltd. which is analyzed using indicators of goal achievement, integration and adaptation. The research method used is a qualitative approach with data collection techniques through literature review, observation and interviews, then analysis and data processing are carried out using reduction techniques and relevant data grouping. The results of the research are presented using descriptive techniques in the Corporate Social Responsibility Program at Energy Equity Epic Sengkang Pty. Ltd. implemented by first communicating, coordinating and socializing with the government and the community. The areas of CSR implementation are education, health, economy, public facilities and the environment. CSR programs implemented meet effectiveness indicators, namely goal achievement, integration and adaptation.
\end{abstract}

Key words: effectiveness, CSR, energy company, environment, health

\section{PENDAHULUAN}

Indonesia adalah sebuah negara dengan sumber daya alam yang melimpah, salah satu yang menjadi sumber daya alam andalan adalah galian tambang meliputi minyak dan gas bumi, batu bara, tembaga, nikel, logam, biji bauksit, dan lain-lain. Apabila sumber daya alam ini dikelola dengan baik maka tentunya akan memberikan kesejahteraan pada masyarakat sesuai amanat pasal 33 ayat (3) UndangUndang Dasar Negara Republik Indonesia Tahun 1945 yang berbunyi, Bumi, air dan kekayaan alam yang terkandung di dalamnya dikuasai oleh Negara dan dipergunakan untuk sebesar-besarnya kemakmuran rakyat (Undang-undang Dasar Negara Republik Indonesia, 1945). Dalam upaya mengelola sumber daya alam khususnya tambang diperlukan kerja sama semua pihak khususnya masyarakat, swasta dan pemerintah agar cita-cita luhur para pendiri bangsa yang dituangkan dalam Undangundang Dasar 1945 dapat tercapai. Dalam pengelolaan sumber daya alam khususnya tambang, pemerintah dapat melaksanakan kegiatan usahanya sendiri melalui Badan Usaha Milik Negara atau disingkat BUMN dan dapat juga melaksanakan kerja sama dengan perusahaan swasta apabila ada kegiatan tertentu yang belum bisa dilaksanakan oleh BUMN.

Badan Usaha Milik Negara (BUMN) maupun perusahaan milik swasta yang mendapatkan hak mengelola kekayaan alam Indonesia di bidang pertambangan memiliki kewajiban berupa tanggung jawab sosial terhadap lingkungan dan masyarakat atau yang dikenal dengan istilah Corporate Social Responsibility (CSR) adapun kegiatan yang dilakukan dalam implementasi CSR antara lain pada sektor lingkungan hidup, kesehatan, pendidikan dan kegiatan sosial. Berbagai dampak sosial, ekonomi, dan lingkungan yang timbul akibat berdirinya suatu kawasan industri, mengharuskan perusahaan untuk bertanggung jawab kepada publik khususnya masyarakat di sekitar wilayah perusahaan melalui aktivitas yang nyata sehingga dalam pelaksanaan 
kegiatan CSR, perusahaan harus berhati-hati dan dilakukan dengan cara-cara yang benar agar tidak memperkuat kondisi relasi ketergantungan dari masyarakat akan kehadiran perusahaan (Budiarti \& Santoso Raharjo, 2013).

Efektivitas Corporate Social Responsibility (CSR) dianggap masih perlu ditingkatkan hal ini terlihat dari masih banyaknya perusahaan yang tidak melaksanakan program sebagai wujud tanggung jawab sosialnya bagi lingkungan dan masyarakat, $\mathrm{Hal}$ ini dikarenakan perusahaan khususnya di bidang pertambangan tidak memperhatikan lingkungan dan masyarakat yang berada di sekitar wilayah pertambangan, perusahaan terlalu fokus mengejar target keuntungan sehingga dampak lingkungan, sosial dan ekonomi menjadi diabaikan.

Tujuan klasik sebuah perusahaan adalah mendapatkan keuntungan untuk membayar para pemegang sahamnya, namun, saat ini, agar bisnis dapat berkelanjutan dalam jangka panjang, diperlukan strategi kegiatan CSR untuk memenuhi tuntutan stakeholders, menghormati prinsip-prinsip etika. dan memberikan jawaban yang tepat kepada pemangku kepentingan organisasi (Hategan et al., 2018).

Dalam beberapa tahun terakhir di Indonesia CSR masih menjadi isu yang terus diperdebatkan oleh pemerintah sebagai pembuat dan pengawas kebijakan, masyarakat sebagai penerima manfaat dan tentunya perusahaan yang memiliki kewajiban CSR, semua pihak hampir tidak menemukan kata sepakat atas implementasi. CSR yang awalnya hanya merupakan kegiatan sukarela perusahaan kini sudah menjadi kewajiban karena banyaknya perusahaan yang tidak memperdulikan kondisi sosial ekonomi dan lingkungan, pemerintah juga melihat fenomena CSR sebagai salah satu solusi masalah sosial masyarakat. Akan tetapi justru CSR disambut masyarakat secara pragmatis dan menggunakannya sebagai alat untuk menekan perusahaan sehingga kadang terjadi hubungan yang tidak sehat antara masyarakat dan perusahaan. Hal ini terjadi ketika harapan masyarakat terhadap CSR terlalu tinggi. Dalam beberapa dekade terakhir, tanggung jawab sosial perusahaan telah menjadi sumber perdebatan yang berkembang antara pemerintah dan swasta, mengenai masalah ketenagakerjaan, globalisasi dan ekspansi di negara-negara dengan kapasitas regulasi dan kebijakan yang lemah yang menyebabkan harapan yang terlalu tinggi bagi nilai sosial lingkungan dan global dari masyarakat sipil terhadap perusahaan (Bruno \& Abriata, 2018). Perusahaan harus mengembalikan sebagian keuntungan yang diperoleh untuk kesejahteraan masyarakat, perbaikan kerusakan yang ditimbulkan, serta memberikan nilai timbal balik kepada para pemangku kepentingan, perusahaan harus melakukan tindakan tanggungjawab sosial, dan menjadi bagian yang tidak terpisahkan dari operasionalnya (Hadi, 2014).

Mengamati kesadaran dan inisiatif perusahaan untuk melaksanakan CSR di bidang pendidikan, kesehatan, ekonomi dan tentunya lingkungan hidup merupakan hal yang sulit untuk diukur. Melihat fenomena perusahaan melaksanakan CSR secara parsial dimana orientasi kegiatan tertentu menjadi fokus kegiatan perusahaan dan mengabaikan sektor kewajiban yang lain. Hampir seluruhnya berorientasi pada keuntungan sumber daya manusia dengan memberikan porsi perhatian yang minim terhadap kelestarian dan pengembangan sumber daya alam dan lingkungan hidup. Mungkin masih ada beberapa perusahaan yang memandang bahwa biaya lingkungan tidak memiliki keberartian yang penting bagi perusahaan. Pandangan seperti ini pada akhirnya menjadi penyebab tidak dianggarkannya dana lingkungan dalam anggaran perusahaan (Gumilar et al., 2017).

\section{METODOLOGI}

Penelitian ini menggunakan pendekatan kualitatif dengan jenis deskriptif. Penelitian deskriptif adalah sebuah penelitian yang bertujuan untuk memberikan atau menjabarkan suatu keadaan atau fenomena yang terjadi saat ini dengan menggunakan prosedur ilmiah untuk menjawab masalah secara aktual (Sugiyono, 2017). Jenis penelitian ini digunakan menggambarkan dan menganalisis efektivitas Program Corporate Social Responsibility (CSR) PT. Energy Equity Epic Sengkang Pty. Ltd kedalam pencapaian tujuan, integrasi program, dan adaptasi organisasi dengan lingkungannya. Terdapat tiga indicator yang sangat mempengaruhi efektivitas yaitu: 
pencapaian tujuan, integrasi dan adaptasi (Duncan, 1985).

Informan pada penelitian ini terdiri dari Camat Gilireng, Kepala Pusat Kesehatan Masyarakat (Puskesmas) Gilireng, Kepala Desa Abbatireng dan Mamminasae, staf Badan Penelitian dan Pengembangan Daerah (BAPPEDA) Kabupaten Wajo, Divisi Corporate Social Responsibility (CSR) PT. Energy Equity Epic Sengkang Pty. Ltd dan masyarakat penerima manfaat. Hasil penyajian data diverifikasi kembali agar penilaian tentang kesesuaian data dengan maksud yang terkandung dalam konsepkonsep dasar dalam penelitian lebih tepat dan objektif, sehingga ditemukan kesimpulan yang tepat.

\section{HASIL PEMBAHASAN}

Energy Equity Epic Sengkang Pty. Ltd. yang beroperasi di Kabupaten Wajo yang secara aktif bergerak di bidang operasi minyak dan gas, menerapkan CSR melalui Implementasi Pedoman Tata Kerja Nomor; PTK-017/SKKO0000/2018/SO. Pedoman ini mengatur hubungan masyarakat dalam hal ini pengembangan masyarakat (Community Development). Pedoman ini dibuat sebagai upaya untuk menciptakan kelembagaan hubungan masyarakat dalam rangka pelayanan informasi yang optimal dan bertanggung jawab, salah satu yang menjadi tugas perusahaan adalah menyalurkan dan menyampaikan CSR yang efektif dan efisien. Energy Equity Epic Sengkang Pty. Ltd. menyalurkan CSR melalui program kerja yang dianggap sangat dibutuhkan masyarakat,. Sebelum program kerja dilaksanakan terlebih dahulu dilakukan pemetaan kebutuhan masyarakat di sekitar perusahaan yang juga melibatkan masyarakat yang dikoordinasikan dengan pemerintah setempat seperti camat dan kepala desa di wilayah perusahaan. Kemudian berdasarkan hal tersebut disusun program kerja yang dianggap paling menyentuh masyarakat.

Respons bisnis yang memadai harus memanifestasikan dirinya di era baru administrator bisnis, bertindak tidak hanya sesuai dengan aturan umum etika bisnis dan prinsip CSR, tetapi juga merancang, merencanakan, dan mengimplementasikan solusi CSR di semua bidang administrasi bisnis (Stonkute et al., 2018). Pelibatan pemerintah dalam program CSR di Kabupaten Wajo melalui Forum Komunikasi Tanggung Jawab Sosial Perusahaan dibawah koordinasi Badan Penelitian dan Pengembangan Daerah Kabupaten Wajo.

Perusahaan wajib memberi pos anggaran untuk kegiatan CSR, untuk Energy Equity Epic Sengkang Pty. Ltd sumber dana berasal dari anggaran Work Planning and Budgeting Program (WP\&B) bidang kehumasan yang telah disetujui oleh Satuan Kerja Khusus Pelaksana Kegiatan Industri Hulu Minyak dan gas (SKK Migas). Sejak diterbitkannya UU Nomor 40 tahun 2007 tentang perseroan terbatas, perusahaan mulai gencar melaksanakan kegiatan CSR yang menjadi sebuah aturan dari pemerintah, nominalnya pun telah ditentukan yakni sebesar $2 \%$ dari profit yang diperoleh perusahaan. Nominal tersebut bisa saja lebih sesuai dengan kebijakan perusahaan tentunya. Namun ada juga perusahaan yang tega mematok nominal sepantasnya untuk pelaksanaan kegiatan Corporate Social Responsibility (Surianto et al., 2016).

\section{Manfaat Corporate Social Responsibility (CSR)}

Keberadaan perusahaan di sebuah daerah menjadi sebuah keberhasilan dalam wujud investasi akan tetapi keberadaan perusahan tentu memiliki dampak positif dan negatif dampak positif adalah terbukanya peluang kerja bagi masyarakat di daerah tersebut baik yang bekerja pada perusahaan maupun sektor-sektor pendukung seperti perdagangan, transportasi dan akomodasi, akan tetapi yang tidak boleh dikesampingkan adalah tentunya dampak negatif yang ditimbulkan oleh berdirinya perusahaan, dampak tersebut bisa berupa dampak sosial dan dampak lingkungan, maka dari itu menjadi kewajiban bagi perusahaan untuk bertanggung jawab secara sosial. Pendekatan semacam ini berkontribusi untuk meningkatkan kualitas hidup dan penerapan konsep pembangunan berkelanjutan (Zelazna et al., 2020).

Corporate Social Responsibility (CSR) setidaknya memberi manfaat pada 3 sektor yaitu perusahaan, pemerintah dan tentunya masyarakat dalam implementasi program CSR Energi Equity Epic Sengkang Pty. Ltd, perusahaan mendapatkan manfaat yaitu dukungan terhadap kegiatan operasional 
agar berjalan baik tanpa adanya gangguan sosial, keamanan, dan lingkungan, secara tidak langsung CSR juga menjadi media promosi perusahaan apabila kegiatan yang dilakukan dapat disaksikan dan dirasakan manfaatnya oleh masyarakat.

Manfaat Corporate Social Responsibility (CSR) Energi Equity Epic Sengkang Pty. Ltd bagi pemerintah setempat dalam hal ini Kecamatan Gilireng Kabupaten Wajo adalah pelibatan Pemerintah Desa, Kecamatan dan Kabupaten mulai dari proses perencanaan, pelaksanaan dan evaluasi sehingga kegiatan maupun program yang dilaksanakan dapat bersinergi dengan program pemerintah baik itu program berbentuk barang maupun jasa sehingga tidak terjadi tumpang tindih kegiatan sehingga pemerintah sangat terbantu dalam pembiayaan maupun dukungan tenaga ahli yang juga disiapkan oleh perusahaan, untuk kegiatan yang berupa infrastruktur pemerintah terlibat sampai pada proses pemeliharaan infrastruktur tersebut. Kehadiran perusahaan melalui kegiatan CSR cukup banyak memberikan kontribusi kepada pemerintah, manfaat tersebut adalah; dukungan pembiayaan, dukungan sarana dan prasarana, dukungan keahlian (Mardikanto, 2014).

Masyarakat Kecamatan Gilireng Kabupaten Wajo sebagai sasaran CSR Energi Equity Epic Sengkang Pty. Ltd merupakan pihak yang harusnya paling merasakan dampak dari program tersebut, Selain dampak pembangunan infrastruktur secara fisik, CSR juga mampu meningkatkan pengalaman masyarakat dalam kegiatan teknis karena pelibatan tenaga ahli sebagai pendamping kegiatan sehingga masyarakat secara tidak langsung belajar dan mengamati cara kerja tenaga ahli pendamping CSR. Dari aspek ekonomi atau kesejahteraan masyarakat program Energi Equity Epic Sengkang Pty. Ltd memfokuskan kegiatan CSR bidang ekonomi yaitu pemberdayaan masyarakat pada usaha sektor pertanian dan peternakan sesuai dengan kondisi sosial ekonomi dan potensi daerah yang dimiliki desa atau masyarakat sasaran. Corporate social responsibility (CSR) dapat dipahami sebagai salah satu bentuk kegiatan yang bertujuan untuk meningkatkan kesejahteraan dan kualitas hidup masyarakat melalui peningkatan kemampuan manusia sebagai individu untuk dapat mengembangkan kemampuan dan meningkatkan kapasitas mereka guna mencapai kemandirian dan kualitas hidup yang lebih baik (Rahmadani et al., 2019).

\section{Bidang-bidang pelaksanaan corporate social responsibility (CSR)}

Dalam pelaksanaan CSR terdapat beberapa bidang atau fokus kegiatan yang dapat menjadi sasaran. Adapun bidang cakupan yang dilaksanakan oleh Energy Equity Epic Sengkang Pty. Ltd. meliputi sektor pendidikan, kesehatan, ekonomi, fasilitas umum dan lingkungan. Dalam penelitian ini, peneliti menyusun data tiga tahun terakhir $(2018,2019,2020)$ tentang bidang-bidang pelaksanaan CSR yang dilakukan oleh Energy Equity Epic Sengkang Pty. Ltd. sebagai berikut;

\section{Pendidikan}

Berdasarkan hasil wawancara dengan pihak pengelola program CSR Energy Equity Epic Sengkang Pty. Ltd. pemerintah setempat dan masyarakat bahwa pada bidang pendidikan, perusahaan menyalurkan beasiswa berprestasi dan kurang mampu, peningkatan pengelolaan dan fasilitas perpustakaan, dan pelatihan peningkatan kapasitas stakeholder bidang pendidikan. Dengan program tersebut dapat disimpulkan bahwa tujuan pelaksanaan CSR telah berjalan sesuai dengan regulasi karena telah membantu terlaksananya pendidikan dalam rangka mencerdaskan kehidupan bangsa sebagai mana yang tercantum dalam pembukaan Undang-undang dasar 1945 (Undang-undang Dasar Negara Republik Indonesia, 1945), serta sesuai dengan Peraturan Daerah Kabupaten Wajo Nomor 23 tahun 2012 Tentang Tanggung Jawab Sosial dan Lingkungan, pasal (12) Bidang Pendidikan dan Kebudayaan terdiri dari kegiatan; pengembangan sarana pendidikan, pengembangan nilai-nilai lokal, beasiswa pendidikan, peningkatan kesejahteraan tenaga guru/pendidik, olahraga dan seni (Peraturan Daerah Kabupaten Wajo Nomor 23 Tahun 2012 Tentang Tanggungjawab Sosial Dan Lingkungan Perusahaan, 2012).

\section{Kesehatan}

Berdasarkan hasil wawancara dengan pihak pengelola program CSR Energy Equity 
Epic Sengkang Pty. Ltd. kepala Pusat Kesehatan Masyarakat Gilireng, dan masyarakat bahwa pada bidang kesehatan, perusahaan telah membantu pengadaan sarana air bersih, revitalisasi posyandu, dukungan fasilitas di Pusat Kesehatan Masyarakat Gilireng, penyediaan mobil layanan kesehatan dan penanganan gizi buruk. Program yang dilaksanakan Energy Equity Epic Sengkang Pty. Ltd. sesuai dengan Peraturan Daerah Kabupaten Wajo nomor 23 tahun 2012 Tentang Tanggung Jawab Sosial dan Lingkungan, pasal (12) yang menyebutkan bahwa bidang kesehatan terdiri dari kegiatan; kesehatan terpadu, bantuan sarana dan prasarana air bersih, keterampilan tenaga medis/kesehatan (Peraturan Daerah Kabupaten Wajo Nomor 23 Tahun 2012 Tentang Tanggungjawab Sosial dan Lingkungan Perusahaan, 2012). Perusahaan memiliki usaha untuk memaksimalisasi keuntungan ekonomis, Namun di sisi lain, perusahaan wajib berkontribusi pada upaya peningkatan kesejahteraan masyarakat dan kesehatan lingkungan melalui program tanggung jawab sosial perusahaan (Utama \& Rizana, 2018).

\section{Ekonomi}

Energy Equity Epic Sengkang Pty. Ltd. melalui CSR bidang ekonomi telah melaksanakan pengembangan ternak sapi bergulir, program ekonomi kreatif, pengembangan usaha kecil menengah yang bekerja sama dengan Badan Usaha Milik Desa (BUMDES). Hal ini sesuai dengan Peraturan Daerah Kabupaten Wajo Nomor 23 tahun 2012 tentang Tanggung Jawab Sosial dan Lingkungan Perusahaan yang menyebutkan bahwa bidang ekonomi terdiri dari kegiatan; peningkatan pendapatan, pelatihan dan keterampilan produk rumah tangga, bantuan peternakan, perikanan, pertanian, konveksi dan peningkatan pendapatan melalui ketenagakerjaan.

Peningkatan kesejahteraan masyarakat suatu daerah merupakan tanggung jawab pemerintah akan tetapi karena keterbatasan sumber daya maka dukungan pihak lain sangat dibutuhkan dalam rangka mencapai target kesejahteraan masyarakat, pihak swasta atau perusahaan merupakan pihak yang memiliki andil sangat besar dalam peningkatan kualitas ekonomi masyarakat selain menyerap tenaga kerja perusahaan juga dapat melakukan kegiatan pengabdian kepada masyarakat melalui program CSR, selain dukungan dana keberadaan perusahaan juga dapat membantu masyarakat meningkatkan keahlian dan pengalaman melalui pelatihan dan peningkatan keterampilan sehingga dapat menciptakan lapangan pekerjaan. Program CSR pada dasarnya dapat dibagi menjadi dua yaitu (1) Program CSR ke dalam adalah program meningkatkan kinerja karyawan, memperhatikan sumber daya manusia, memberikan fasilitas kepada karyawan dan keluarga karyawan (2) program CSR ke luar yaitu berupa community development yang berpola pikir kepada pengembangan masyarakat khususnya masyarakat sekitar perusahaan (Heriyanto et al., 2016).

\section{Fasilitas Umum}

Pengadaan fasilitas umum yang layak merupakan tanggung jawab pemerintah, tetapi keterlibatan pihak swasta dan perusahaan dalam pengadaan fasilitas umum sangat diharapkan mengingat keterbatasan sumber daya dari pemerintah. Pemerintah perlu mencari solusi atas persoalan tersebut dengan melibatkan berbagai stakeholder terkait dalam pelaksanaan pembangunan, misalnya pihak swasta, masyarakat, lembaga swadaya masyarakat, dan NGO. Keterlibatan berbagai pihak ini memiliki peran penting untuk membantu pemerintah mengingat tidak semua aktivitas pembangunan mampu dikerjakan oleh pemerintah sendiri terutama dalam hal ketersediaan keahlian sumber daya manusia dan finansial sehingga perlu keterlibatan pihak swasta, bentuk kerja sama yang melibatkan pihak swasta ini dikenal dengan public private partnership (Latifah \& Aziz, 2016).

Energy Equity Epic Sengkang Pty. Ltd. melalui program CSR telah membantu pengadaan fasilitas umum berupa, pembangunan ruang terbuka hijau (RTH), pembenahan lapangan olah raga, pembangunan masjid, pembangunan jembatan, pembenahan Pusat Kesehatan Masyarakat (PKM), perbaikan posyandu, bantuan perbaikan pasar rakyat. Hal ini memperlihatkan kepedulian perusahaan terhadap penyediaan dan perbaikan fasilitas umum sesuai dengan Peraturan Daerah Kabupaten Wajo nomor 23 tahun 2012 
tentang Tanggung Jawab Sosial dan Lingkungan Perusahaan yang menyebutkan bahwa bidang fasilitas umum dan sosial terdiri dari kegiatan pembangunan infrastruktur berupa jalan dan jembatan, pengembangan sarana MCK dan panti asuhan (Peraturan Daerah Kabupaten Wajo Nomor 23 Tahun 2012 Tentang Tanggungjawab Sosial Dan Lingkungan Perusahaan, 2012). Munculnya program pembangunan dalam CSR tidak terlepas dari pandangan bahwa pembangunan termasuk pembangunan daerah tidak saja merupakan tanggung jawab pemerintah saja tetapi tanggung jawab semua pihak termasuk di dalamnya pihak perusahaan baik Badan Usaha Milik Negara (BUMN) maupun perusahaan swasta (Erfit, 2017).

\section{Lingkungan}

Energy Equity Epic Sengkang Pty. Ltd. melalui program CSR telah membantu pengadaan tempat sampah pada rumah tangga di Kecamatan Gilireng dan Kota Sengkang, dan kegiatan pemanfaatan pekarangan rumah masyarakat. Kegiatan tersebut menunjukkan adanya kepedulian dari pihak perusahaan terhadap kebersihan lingkungan dan pemanfaatan lahan pekarangan untuk penyediaan tanaman obat keluarga, sesuai Peraturan Daerah Kabupaten Wajo No.5 Tahun 2006 tentang Pengelolaan Kebersihan dan Keindahan dalam wilayah Kabupaten Wajo, dan Peraturan Daerah Kabupaten Wajo nomor 23 tahun 2012 tentang Tanggung Jawab Sosial dan Lingkungan Perusahaan yang pasal 12 menyebutkan bahwa bidang lingkungan terdiri dari kegiatan; reklamasi pantai dan penanaman bakau, pengelolaan sampah rumah tangga, hubungan masyarakat dengan kesadaran lingkungan.

Masalah sampah di Indonesia merupakan masalah yang kompleks karena kurangnya pengertian masyarakat terhadap akibatakibat yang dapat ditimbulkan oleh sampah, faktor lain yang menyebabkan permasalahan sampah di Indonesia semakin rumit adalah meningkatnya taraf hidup masyarakat, yang tidak disertai dengan keselarasan pengetahuan tentang persampahan dan juga partisipasi masyarakat yang kurang untuk memelihara kebersihan dan membuang sampah pada tempatnya (Aditya et al., 2015).

\section{Efektifitas Pelaksanaan Corporate Social Responsibility (CSR)}

Efektivitas sebuah program diukur berdasarkan sejauh mana program tersebut dapat mengatasi masalah secara berdaya guna dan berhasil guna. Corporate Social Responsibility (CSR) adalah sebuah tanggung jawab perusahaan untuk mengatasi masalah sosial di masyarakat baik yang timbul sebelum keberadaan perusahaan maupun masalah yang timbul akibat berdirinya perusahaan tersebut, CSR adalah sebuah program yang dirancang sebagai solusi masalah sosial di masyarakat yang diharapkan dapat diimplementasikan secara efektif. Indikator tingkat efektivitas Program CSR Energy Equity Epic Sengkang Pty. Ltd. berdasarkan teori Duncan yang menjelaskan bahwa terdapat tiga indikator yang sangat mempengaruhi efektivitas yaitu; pencapaian tujuan, integrasi dan adaptasi (Duncan, 1985).

\section{Pencapaian tujuan}

Pelaksanaan CSR Energy Equity Epic Sengkang Pty. Ltd. pada bidang pendidikan dengan kegiatan menyalurkan beasiswa berprestasi dan kurang mampu, peningkatan pengelolaan dan fasilitas perpustakaan, dan pelatihan peningkatan kapasitas stakeholder bidang pendidikan bertujuan untuk membantu anak usia sekolah yang beresiko putus sekolah karena masalah keuangan orang tua, meningkatkan motivasi belajar siswa agar berprestasi, meningkatkan minat literasi siswa melalui sarana perpustakaan yang lengkap dan meningkatkan kualitas guru dan tenaga pengajar agar mampu memberikan pendidikan yang berkualitas sesuai dengan kebutuhan dunia kerja. Demikian adanya, antara perusahaan dan masyarakat adalah saling menjaga kepentingannya, dan yang lebih khusus lagi adalah penyelenggaraan pendidikan (Hadisuamardjo, 2014).

Pelaksanaan CSR pada bidang kesehatan dengan kegiatan pengadaan sarana air bersih, revitalisasi posyandu, dukungan fasilitas di Pusat Kesehatan Masyarakat (PKM) Gilireng, mobil layanan kesehatan, dan penanganan gizi buruk. Kegiatan kegatan tersebut bertujuan untuk menjawab kebutuhan dasar masyarakat akan air bersih mengingat Kecamatan Gilireng termasuk daerah yang kesulitan mendapatkan air 
bersih. Perbaikan dan dukungan fasilitas pada sarana kesehatan Posyandu dan PKM bertujuan untuk meningkatkan kualitas pelayanan bagi masyarakat yang membutuhkan informasi maupun perawatan kesehatan begitu pula dengan penanganan gizi buruk yang masih menjadi salah satu masalah nasional di bidang kesehatan sehingga dibutuhkan dukungan berbagai pihak. Berbagai upaya peningkatan kesehatan masyarakat telah dilakukan oleh berbagai pihak, salah satunya oleh perusahaan melalui kegiatan CSR. Dalam pelaksanaannya, kegiatan CSR yang dilakukan tersebut hendaknya dialamatkan pada keempat faktor kesehatan, yakni perilaku, lingkungan, pelayanan kesehatan, dan hereditas (Indah et al., 2014).

Pelaksanaan CSR Energy Equity Epic Sengkang Pty. Ltd pada bidang ekonomi melalui kegiatan pengembangan ternak sapi bergulir, program ekonomi kreatif, pengembangan usaha kecil menengah yang bekerja sama dengan Badan Usaha Milik Desa (BUMDES). Kegiatan bertujuan untuk meningkatkan taraf hidup masyarakat melalui peningkatan keahlian dan menumbuhkan kreativitas sehingga dapat meningkatkan penghasilan. Program CSR kemudian secara luas dipahami sebagai komitmen berkelanjutan organisasi atau korporasi untuk bertindak secara etis, mendukung pembangunan ekonomi masyarakat, serta memperbaiki kualitas kehidupan pekerja, keluarga, masyarakat lokal dan masyarakat yang lebih luas (Prajarto, 2015).

Pelaksanaan CS Energy Equity Epic Sengkang Pty. Ltd pada bidang fasilitas umum melalui kegiatan, pembangunan ruang terbuka hijau (RTH), pembenahan lapangan olah raga, pembangunan masjid, pembangunan jembatan, pembenahan Pusat Kesehatan Masyarakat (PKM), perbaikan posyandu dan bantuan perbaikan pasar rakyat. Kegiatan ini bertujuan membantu pemerintah dalam perbaikan dan pengadaan fasilitas umum mengingat keterbatasan sumber daya yang dimiliki pemerintah sehingga dibutuhkan kemitraan dengan sektor swasta. Infrastruktur menjadi salah satu aspek yang mendapat perhatian perusahaan melalui aktivitas CSR dengan tujuan meningkatkan kualitas infrastruktur pedesaan untuk peningkatan kegiatan sosialekonomi masyarakat (Andraina, 2014).
Pelaksanaan CSR pada bidang lingkungan melalui kegiatan pengadaan tempat sampah pada rumah tangga di Kecamatan Gilireng dan Kota Sengkang, dan kegiatan pemanfaatan pekarangan rumah masyarakat untuk tanaman obat keluarga (TOGA). Tujuan program adalah untuk meningkatkan kesadaran masyarakat akan pentingnya hidup sehat yang dimulai dengan menjaga kebersihan lingkungan dan pemanfaatan tanaman alami untuk pengobatan herbal melalui program TOGA di pekarangan rumah masyarakat. Begitu pentingnya isu lingkungan, hingga sebagian besar pemerintahan di berbagai negara mengeluarkan berbagai kebijakan khusus berkenaan implementasi CSR peduli lingkungan (Feronika et al., 2020).

Program CSR Energy Equity Epic Sengkang Pty. Ltd apabila dianalisis menggunakan pendapat Duncan maka terlihat bahwa kegiatan CSR yang dilaksanakan sesuai dengan visi misi organisasi, begitu pula dengan proses, penetapan, implementasi dan evaluasi. Program CSR yang telah mengakomodir visi dan misi perusahaan yaitu mampu meningkatkan kesejahteraan masyarakat melalui CSR bidang pendidikan, kesehatan dan ekonomi serta memberikan nilai tambah bagi masyarakat dan pembangunan daerah melalui CSR bidang fasilitas umum dan lingkungan.

\section{Integrasi}

Salah satu masalah pembangunan di Indonesia adalah sinergitas antara para pembuat kebijakan dalam perencanaan pembangunan yang terintegrasi. Peran berbagai pihak dalam pembangunan baik di tingkat nasional maupun daerah sudah signifikan akan tetapi terkendala oleh tumpang tindih kebijakan yang terkadang kurang koordinasi antara pemangku kepentingan, sehingga menciptakan program kerja yang tidak terintegrasi. Regulasi mengenai koordinasi dan integrasi pembangunan nasional telah dituangkan dalam Undang-Undang, tetapi kesadaran untuk menjalankan regulasi tersebut masih rendah. Tujuan perencanaan pembangunan nasional menurut Undang-Undang Nomor 25 Tahun 2004, antara lain; Mendukung koordinasi antar pelaku pembangunan Menjamin terciptanya integrasi, sinkronisasi, 
dan sinergi baik antardaerah, antar-ruang, antar-waktu, antar-fungsi pemerintah maupun antara Pusat dan Daerah, Menjamin keterkaitan dan konsistensi antara perencanaan, penganggaran, pelaksanaan dan pengawasan Mengoptimalkan partisipasi masyarakat dan menjamin tercapainya penggunaan sumber daya secara efisien, efektif, berkeadilan dan berkelanjutan (Undang-undang Nomor 25 Tahun 2004 tentang Sistem Perencanaan Pembangunan Nasional, 2004).

\section{Adaptasi}

Salah satu program perusahaan yang wajib mengadaptasi fenomena sosial masyarakat adalah Corporate Social Responsibility (CSR). Budaya organisasi dikatakan sebagai pembelajaran untuk mengatasi masalah adaptasi terhadap eksternal perusahaan yang dibawa masuk ke dalam internal organisasi, diasumsikan, bila perusahaan sudah menanamkan budaya secara kuat maka lebih mudah untuk melakukan adaptasi terhadap perubahan lingkungan eksternal (Schein, 2010).

Berdasarkan hasil wawancara dengan pihak pengelola CSR Energy Equity Epic Sengkang Pty. Ltd, bahwa perusahaan senantiasa terbuka melakukan penyesuaian sepanjang memiliki dasar hukum yang kuat dan benar. Perubahan kebijakan pengelolaan CSR memungkinkan untuk dilaksanakan apabila tidak bertentangan dengan aturan yang berlaku. Kemampuan adaptasi perusahaan pada program CSR memang sangat dibutuhkan mengingat dinamika masyarakat dan regulasi dari pemerintah yang sangat dinamis demi menjawab kebutuhan masyarakat. Korporasi bukan lagi sebagai entitas yang hanya mementingkan dirinya sendiri saja (selfish) sehingga teralienasi atau mengasingkan diri dari lingkungan masyarakat di tempat mereka bekerja, melainkan sebuah entitas usaha yang wajib melakukan adaptasi kultural dengan lingkungan sosialnya, agar pelaksanaan CSR tidak hanya sekadar "having fun" para pengusaha, maka perlu peran pemerintah mengawalnya, sehingga transformasi pelaksanaan CSR dapat memenuhi harapan masyarakat dan stakeholders (Riyadi, 2010).

\section{KESIMPULAN}

Energy Equity Epic Sengkang Pty. Ltd. menyalurkan Corporate Social Responsibility (CSR) melalui program kerja yang dianggap sangat dibutuhkan masyarakat, sebelum program kerja dilaksanakan terlebih dahulu dilakukan pemetaan kebutuhan masyarakat di sekitar perusahaan yang juga melibatkan masyarakat yang dikoordinasikan dengan pemerintah setempat seperti camat dan kepala desa di wilayah perusahaan, kemudian berdasarkan hal tersebut disusun program kerja yang dianggap paling menyentuh masyarakat. Dalam pelaksanaan CSR terdapat beberapa bidang atau fokus kegiatan yang dapat menjadi sasaran, meliputi sektor pendidikan, kesehatan, ekonomi, fasilitas umum dan lingkungan.

Efektivitas CSR apabila dilihat dari sisi pencapaian tujuan telah sesuai dengan visi misi organisasi, begitu pula dengan proses, penetapan, implementasi dan evaluasi CSR yang telah mengakomodir visi dan misi perusahaan yaitu mampu meningkatkan kesejahteraan masyarakat melalui CSR bidang pendidikan, kesehatan dan ekonomi serta memberikan nilai tambah bagi masyarakat dan pembangunan daerah melalui CSR bidang fasilitas umum dan lingkungan.

Berdasarkan sisi integrasi Energy Equity Epic Sengkang Pty. Ltd melalui program CSR 5 bidang yaitu; pendidikan, kesehatan, ekonomi, fasilitas umum dan lingkungan selalu menjalin komunikasi, koordinasi dan melaksanakan sosialisasi dalam proses, penetapan, implementasi dan evaluasi CSR. Hal ini dilakukan agar tercipta program yang terintegrasi dengan kebijakan pemerintah yang berasal dari aspirasi masyarakat. Berdasarkan sisi adaptasi Corporate Social Responsibility (CSR) Energy Equity Epic Sengkang Pty. Ltd, senantiasa terbuka melakukan penyesuaian sepanjang memiliki dasar hukum yang kuat dan benar. Perubahan kebijakan pengelolaan CSR karena keinginan masyarakat dan kebijakan pemerintah dapat dilaksanakan apabila tidak bertentangan dengan aturan yang berlaku. Berdasarkan hal tersebut dapat disimpulkan bahwa program CSR Energy Equity Epic Sengkang Pty. Ltd memenuhi standar efektivitas jika dianalisis menggunakan indikator pencapaian tujuan, integrasi dan adaptasi. 


\section{DAFTAR PUSTAKA}

Aditya, R., Kiki, P., Utomo, P., \& Rahayu, D. (2015). Perilaku Masyarakat dalam membuang sampah di Tempat Penampungan Sementara ( TPS ) di Kecamatan Pontianak Barat Kota Pontianak. 1-10.

Andraina, S. (2014). Aktivitas Corporate Social Responsibility (CSR) Sebagai Upaya Dalam Meningkatkan Citra Perusahaan ( Studi Pada PT Energi Mega Persada Bentu \& Korinci Baru Di Pekanbaru ). Journal Online Mahasiswa Fakultas IImu Sosial Dan IImu Politik Universitas Riau, 1-11.

Da Silveira, L. M., \& Petrini, M. (2018). Sustainable Development and Corporate Social Responsibility: A bibliometric analysis of International Scientific Production. Gestao e Producao. https://doi.org/10.1590/0104-530X317316

Delautre Bruno, G., \& Abriata, D. (2018). Corporate Social Responsibility: Exploring determinants and complementarities. 38. https://www.ilo.org/wcmsp5/groups/public /---dgreports/---

inst/documents/publication/wcms_654735 .pdf

Duncan, J. W. (1985). Organization Behavior. Houghton Mifflin.

Elkington, J. (1998). Partnerships from cannibals with forks: The triple bottom line of 21st-century business. Environmental Quality Management. https://doi.org/10.1002/tqem.3310080106

Erfit. (2017). Pemanfaatan Dana Corporate Social Responsibility (CSR) Untuk Pembiayaan Pembangunan Pertanian di Provinsi Jambi. Jurnal Perspektif Pembiayaan Dan Pembangunan Daerah, 4(3), 2338-4603. https://media.neliti.com/media/publication s/125028-ID-pemanfaatan-danacorporate-social-respon.pdf

Feronika, E. S., Silva, K. R., Raharjo, S. T., \& Resnawaty, R. (2020). Tanggung Jawab Sosial Perusahaan Bidang Lingkungan. Prosiding Penelitian Dan Pengabdian
Kepada Masyarakat, 7(1), 1. https://doi.org/10.24198/jppm.v7i1.28557

Fontaine, M. (2013). Corporate Social Responsibility and Sustainability: The New Bottom Line? In International Journal of Business and Social Science.

Gumilar, S., Rachim, H. a., \& Meilanny, L. (2017). Tanggung Jawab Sosial Perusahaan ( Csr ) Studi Efektifitas Program Pt. Pertamina Sehati (Sehat Ibu Dan Anak Tercinta). Prosiding Penelitian Dan Pengabdian Kepada Masyarakat, 4(2), $\quad$ 235-240. https://doi.org/10.24198/jppm.v4i2.14291

Hadi, N. (2014). Corporate Social Reponsibility. Graha IImu.

Hadisuamardjo, H. (2014). Efektivitas Implementasi Kebijakan Program Csr Dalam Bidang Pendidikan. Jurnal Administrasi Pendidikan UPI, 21(2), 5167.

https://doi.org/10.17509/jap.v21i2.6675

Hategan, C. D., Sirghi, N., Curea-Pitorac, R. I., \& Hategan, V. P. (2018). Doing well or doing good: The relationship between corporate social responsibility and profit in Romanian companies. Sustainability (Switzerland), 10(4). https://doi.org/10.3390/su10041041

Heriyanto, M., Adianto, Dan, \& Hasim, A. (2016). Program Corporate Social Responsibility dalam Perspektif Indeks Kepuasan Publik di Riau. Sosio Konsepsia, 6(01), 90-109. http://www.kelloggcompany.com/content/ dam/kelloggcompanyus/corporate_respo nsibility/pdf/2008-

2010/Kelloggs_2008CRR_FullReport.pdf

Indah, G., Rachim, H. A., \& Irfan, M. (2014). Promosi Kesehatan Ibu Dan Anak Melalui Corporate Social Responsibility (Csr) Bidang Kesehatan Ibu Dan Anak. Share: Social Work Journal, 4(2). https://doi.org/10.24198/share.v4i2.13065

Karim, A. (2018). Mengembangkan Kesadaran Melestarikan Lingkungan Hidup Berbasis Humanisme Pendidikan Agama. Edukasia: Jurnal Penelitian Pendidikan Islam, 12(2), 309. https://doi.org/10.21043/edukasia.v12i2.2 780 
Latifah, N., \& Aziz, L. (2016). Hubungan Kerjasama Pemerintah dengan Pihak Swasta dalam Pembangunan Infrastruktur di Indonesia. Pusat Penelitian Politik LIPI. http://www.politik.lipi.go.id/kolom/kolom1/politik-lokal/1107-hubungan-kerjasamapemerintah-dengan-pihak-swasta-dalampembangunan-infrastruktur-di-indonesia

Ltd, E. E. E. (Sengkang) P. (2020). Visi Misi Energy Equity Epic (Sengkang) Pty Ltd. Energy Equity Epic (Sengkang) Pty Ltd. http://www.energyequity.co.id/visi-danmisi-kami

Mardikanto, T. (2014). CSR (Tanggungjawab Sosial Korporasi). Alfabeta.

Meilanny Budiarti S. \& Santoso Tri Raharjo. (2013). Corporate Social Responsibility (CSR) dari Sudut Pandang Perusahaan. Profession and Purpose: A Resource Guide for MBA Careers in Sustainability, 48-56. https://doi.org/10.9774/gleaf.9781-907643-08-8_12

Peraturan Daerah Kabupaten Wajo No.5 Tahun 2006 tentang Pengelolaan Kebersihan dan Keindahan dalam wilayah Kabupaten Wajo, (2006).

Peraturan Daerah Kabupaten Wajo Nomor 23 Tahun 2012 Tentang Tanggungjawab Sosial Dan Lingkungan Perusahaan, 53 Pemerintah Kabupaten Wajo 1689 (2012).

Undang-undang Dasar Negara Republik Indonesia, (1945).

Prajarto, N. (2015). Corporate Social Responsibility dan Pengembangan Ekonomi Kreatif Berbasis Media, Desain, dan IPTEK. JURNAL IPTEKKOM : Jurnal Ilmu Pengetahuan \& Teknologi Informasi, 17(2),

161. https://doi.org/10.33164/iptekkom.17.2.20 15.161-174

Prutina, Ž. (2016). The effect of corporate social responsibility on organizational commitment. Management: Journal of Contemporary Management Issues.

Rahmadani, R., Raharjo, S. T., \& Resnawaty, R. (2019). Fungsi Corporate social responsibility (CSR) Dalam Pengembangan dan Pemberdayaan Masyarakat. Share: Social Work Journal, $8(2)$,

203. https://doi.org/10.24198/share.v8i2.20081

Ridho, T. K. (2018). The Development of CSR Implementation in Indonesia and Its Impact on Company's Financial and Nonfinancial Performance. KnE Social Sciences.

https://doi.org/10.18502/kss.v3i8.2517

Riyadi, R. (2010). Transformasi Pelaksanaan Corporate Social Responsibility (CSR) dalam Pengembangan Masyarakat ( Community Development ). Interaktif, 3(2), $1-12$.

Schein, E. H. (2010). Organizional Culture and Leadership. In Organizational Culture and Leadership.

Stonkute, E., Vveinhardt, J., \& Sroka, W. (2018). Training the CSR sensitive mindset: The integration of CSR into the training of business administration professionals.

(Switzerland). https://doi.org/10.3390/su10030754

Sugiyono. (2017). MetodePenelitian Kuantitatif, Kualitatif dan R\&D. Bandung: PT Alfabet. In Sugiyono. (2017). MetodePenelitian Kuantitatif, Kualitatif dan $R \& D$. Bandung: PT Alfabet.

Surianto, B., Mone, A., \& Said, A. (2016). Corporate Social Responsibility Energy Equity Epic ( Sengkang) PTY . Ltd Dalam Meningkatkan Pembangunan Berkelanjutan Di Desa Poleonro Kecamatan Gilireng Kabupaten Wajo. Jurnal IImu Administrasi, 5.

Triyanto, D. (2015). Pelaksanaan Corporate Social Responsibility (CSR) Di Bidang Pendidikan PT. Hino Motors Sales Indonesia (PT. HMSI). In Biomass Chem Eng.

Undang-undang Nomor 25 Tahun 2004 tentang Sistem Perencanaan Pembangunan Nasional, (2004).

Utama, A. S., \& Rizana. (2018). Penegakan Hukum Terhadap Pelaksanaan Tanggung Jawab Sosial Perusahaan Di Kecamatan Rumbai Pekanbaru. Journal Equitable, 3(1), 1-11.

Wang, H., Tong, L., Takeuchi, R., \& George, G. (2016). Corporate social responsibility: An overview and new research directions. 
In Academy of Management Journal. https://doi.org/10.5465/amj.2016.5001

Yuniarti Wahyuningrum, Irwan Noor, A. W. (2014). Pengaruh Program Corporate Social Responsibility Terhadap Peningkatan Pemberdayaan Masyarakat (Studi Pada Implementasi CSR PT. Amerta Indah Otsuka Desa Pacarkeling Kecamatan Kejayan Kabupaten
Pasuruan). Jurnal Administrasi Publik Mahasiswa Universitas Brawijaya.

Zelazna, A., Bojar, M., \& Bojar, E. (2020). Corporate social responsibility towards the environment in Lublin region, Poland: $A$ comparative study of 2009 and 2019. Sustainability (Switzerland), 12(11). https://doi.org/10.3390/su12114463 